\title{
Differences in diversity and photoprotection capability between Ice algae and under-ice phytoplankton in Saroma-Ko Lagoon, Japan: a comparative taxonomic diatom analysis with microscopy and DNA barcoding
}

\author{
Kazuhiro Yoshida ${ }^{1,2,3}$, Hiroshi Hattori ${ }^{4}$, Takenobu Toyota ${ }^{5}$, Andrew McMinn ${ }^{2}$ and Koji Suzuki ${ }^{1}$ \\ ${ }^{1}$ Faculty of Environmental Earth Science, Hokkaido University \\ ${ }^{2}$ Institute for Marine and Antarctic Studies \\ ${ }^{3}$ Graduate School of Agriculture, Saga University \\ ${ }^{4}$ Department of Marine Biology and Sciences, Tokai University \\ ${ }^{5}$ Insitute of Low Temperature Science, Hokkaido University
}

Sea ice algae are the main primary producers in polar ecosystems (Arrigo, 2017). Bottom communities are particularly composed of diatoms with the highest biomass (Horner, 1985; van Leeuwe et al., 2018). Ice algae are unique and diverse communities. Although young ice communities usually reflect the composition of the underlying seawater when ice forms, species selection in sea ice over time can change the community composition of ice algae from that of under-ice phytoplankton. However, less attention has been paid on the difference or similarity in community composition between sea ice and under-ice. The taxonomy of sea ice communities has been traditionally investigated with light microscopy. Recently, molecular techniques, including pigment analysis, have provided new insights into the diversity and physiology of sea-ice communities (Hardge et al. 2017; Yoshida et al., 2020). However, no comparative taxonomic survey has been conducted for ice algae thus far. Here, we investigated differences and similarities in (1) the diversity and (2) the photosynthetic strategies of diatom communities in sea ice and the underlying seawater of Saroma-Ko Lagoon, Hokkaido, Japan, using algal pigment signatures determined by ultrahigh performance liquid chromatography (Suzuki et al., 2015), light and scanning electron microscopy (hereafter LM and SEM, respectively, Nosaka et al., 2017; Roukaerts et al., 2018) and Ion Torrent next-generation sequencing (NGS) techniques targeting the 18S rRNA gene (i.e., DNA barcoding) (Endo et al., 2018; Yoshida et al., 2018). Ice algae typically possessed greater biomass (> 20-fold) and chlorophyll (chl) $a$ breakdown products than under-ice phytoplankton, suggesting that the ice algae formed blooms, and cell senescence and disruption could be significant mitigating factors. LM and SEM showed a good agreement for the ice algal community compositon. However, LM overlooked small species of under-ice seawater. Although the results of NGS were neither consistent with those of LM nor SEM, this method successfully identified some easily-misidentified species by microscopy. We concluded that SEM would be the most reliable method to identify ice algae and under-ice phytoplankton. Although NGS cannot be used for sea ice taxonomy work at this stage, NGS can provide useful auxiliary information on their identification. Further molecular investigations of ice algae, including the expansion of nucleotide databases, are needed (Rimet et al., 2019). The diversity of diatoms in sea ice was higher than in under-ice seawater, although the evenness was comparable or lower in ice algae than in under-ice phytoplankton (Fig. 1). Ice algae had a larger xanthophyll pool size and a higher ratio of photoprotective to photosynthetic pigments (11-fold and 4.5-fold higher, respectively) than under-ice phytoplankton. The results indicated that ice algae were well adapted to changes in the light regime, which could partly support their survival capability and high taxonomic diversity.

\section{Ice algae}

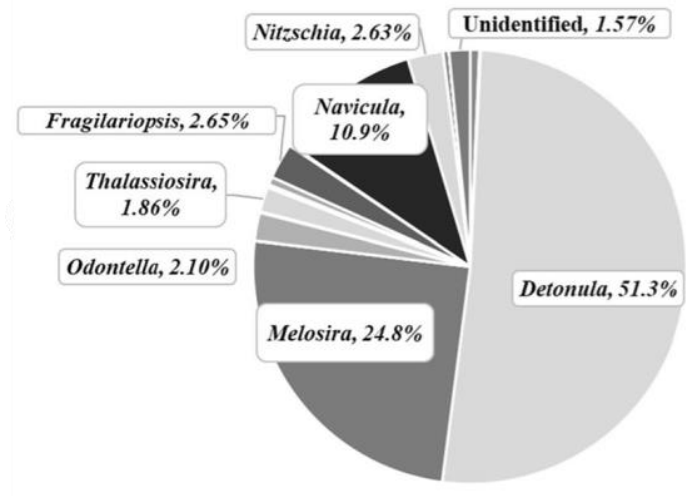

\section{Under-ice phytoplankton}

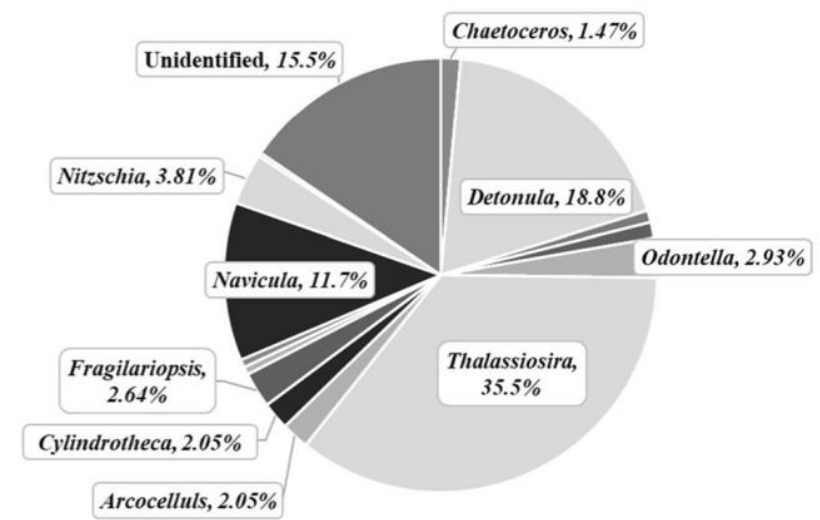

Figure 1. Diatom community composition in sea ice and under-ice seawater determined by scanning electron microscopy (SEM). The left and right panels show the taxonomic results of ice algae and under-ice phytoplankton, respectively. 


\section{References}

Arrigo, K.R., Sea ice as a habitat for primary producers, In: Thomas, D.N. (ed.), Sea Ice, 3rd edition, Wiley-Blackwell, pp. 352-369, 2017.

Endo, H., H. Ogata and K. Suzuki, Contrasting biogeography and diversity patterns between diatoms and haptophytes in the central Pacific Ocean, Scientific Reports, 8, 10916, 2018.

Hardge, K., I. Peeken, S. Neuhaus, Lange, B.A., A. Stock, T. Stoeck, L. Weinisch and K. Metfies, The importance of sea ice for exchange of habitat-specific protist communities in the Central Arctic Ocean, Journal of Marine Systems, 165, 124-138, 2017.

Honer, R.A., Sea Ice Biota, CRC Press, 215 pp.

Nosaka, Y., Y. Yamashita and K. Suzuki, Dynamics and origin of transparent exopolymer particles in the Oyashio region of the western subarctic Pacific during the spring diatom bloom, Frontiers in Marine Science, 4, 79, 2017.

Piwosz, K., J.M. Wiktor, A. Niemi, A. Tatarek and C. Michel, Mesoscale distribution and functional diversity of picoeukaryotes in the first-year sea ice of the Canadian Arctic, The ISME Journal, 7, 1461-1471, 2013.

Rimet, F., E. Gusev, M. Kahlert, M.G. Kelly, M. Kulikovskiy, Y. Maltsev, D.G. Mann, M. Pfannkuchen, R. Trobajo, V. Vasselon, J. Zimmermann and A. Bouchez, Diat.barcode, an open-acces curated barcode library for diatoms, Scientific Reports, 9:15116, 2019.

Roukaerts, A., D. Nomura, F. Deman, H. Hattori, F. Dehairs and F. Fripiat, The effect of melting treatments on the assessment of biomass and nutrients in sea ice (Saroma-ko lagoon, Hokkaido, Japan), Polar Biology, 42, 347-356, 2018.

Suzuki, K., A. Kamimura and S.B. Hooker, Rapid and highly sensitive analysis of chlorophylls and carotenoids from marine phytoplankton using ultra-high performance liquid chromatography (UHPLC) with the first derivative spectrum chromatogram (FDSC) technique, Marine Chemistry, 176, 96-109, 2015.

van Leeuwe, M.A., L. Tedesco, K.R. Arrigo, P. Assmy, K. Campbell, K.M. Meiners, J.-M. Rintala, V. Selz, D.N. Thomas and J. Stefel, Microalgal community structure and primary production in Arctic and Antarctic sea ice: A synthesis, Elementa, 6, 4, 2018.

Yoshida, K., H. Endo, E. Lawrenz, T. Isada, S.B. Hooker, O. Prášil and K. Suzuki, Community composition and photophysiology of phytoplankton assemblages in coastal Oyashio waters of the western North Pacific during early spring, Estuarine, Coastal and Shelf Science, 212, 80-94, 2018.

Yoshida, K, A. Seger, F. Kennedy, A. McMinn and K. Suzuki, Freezing, melting, and light stress on the photophysiology of ice algae: Ex situ incubation of the ice algal diatom Fragilariopsis cylindrus (Bacillariophyceae) using an ice tank, Journal of Phycology, 43, 1873-1885, 2020. 